\title{
Escapando da narrativa de Plutarco: uma reconstrução da vida de Demétrio, o Sitiador de Cidades
}

\author{
Escaping Plutarch's narrative: a reconstruction of the life of \\ Demetrius, the besieger of cities
}

WHEATLEY, P.; DUNN, C. Demetrius the Besieger. Oxford: Oxford
University Press, 2020. 528 p.

Jorel Musa de Noronha Lemes*

Recebido em: 03 maio 2021

Aprovado em: 08 jul. 2021

\begin{abstract}
0 egundo Bernardino (2020, p. 68), "os estudos sobre o período helenístico têm ganhado fôlego vigoroso com a apresentação de novas respostas e de novas perguntas". Em particular, desde a década de 1990 é expressiva a quantidade de trabalhos que possuem como objeto de estudo a vida de diádocos específicos, os sucessores de Alexandre Magno. Conforme pontuam Wheatley e Dunn (2020), alguns destes indivíduos chegaram a ter diversas biografias dedicadas às suas vidas desde a década de 1990, e este é o caso de Antígono Monoftalmo, pai de Demétrio Poliorcetes. A vida e/ou o reino de Antígono Monoftalmo recebem uma atenção quase que exclusiva em diversas pesquisas, como a biografia escrita por Jeff Champion (2014), a tese de Alessandra André (2018) e a obra escrita por Richard Billows (1990), autor que, para Sant'Anna (2012, p. 234), produziu o trabalho mais completo sobre este diádoco entre aqueles produzidos até então.

Como filho de Antígono Monoftalmo e seu co-regente, Demétrio Poliorcetes mantém-se longe de ser ignorado em tais obras, mas geralmente a sua confusa e caótica jornada após a Batalha de Ipso, em 301 a.C., quando seu pai faleceu em combate, recebe apenas uma breve contextualização, como se fosse composta por uma reflexão tardia. Assim, para Wheatley e Dunn (2020), existia uma importante lacuna nos estudos modernos
\end{abstract}

* Mestre em Relações Internacionais pela Pontifícia Universidade Católica de Minas Gerais. 
dos diádocos e de seus conflitos, pois a vida de Demétrio não havia sido abordada com a atenção necessária para a compreensão da trajetória deste importante diádoco. Por conseguinte, eles juntaram esforços para produzirem uma biografia de Demétrio Poliorcetes, e o volume publicado é fruto de uma pesquisa acadêmica que percorreu três décadas. Notavelmente, a obra Demetrius the Besieger é apenas o segundo trabalho acadêmico dedicado exclusivamente à vida de Demétrio Poliorcetes, que foi publicado desde quando Plutarco escreveu as Vidas Paralelas de Demétrio e Marco Antônio, no início do século I.

Entre a introdução e a conclusão da obra, Demetrius the Besieger possui 27 capítulos, os quais seguem cronologicamente a vida deste diádoco, desde seu nascimento, em 336 a.C. e sua infância e juventude na Frígia, enquanto Alexandre Magno avançava cada vez mais ao Leste na Ásia, até o seu falecimento, em 282 a.C., após permanecer três anos como prisioneiro de Seleuco. Por fim, o volume possui dois apêndices, o primeiro sobre o Colosso de Rodes - construído em comemoração à defesa desta cidade durante o longevo sítio comandado por Demétrio Poliorcetes entre 305 a.C. e 304 a.C. - e o segundo constituindo-se numa cronologia da vida de Demétrio.

$\mathrm{Na}$ introdução, os autores contextualizam, mesmo que brevemente, a Era dos Diádocos e estabelecem o estado da arte, apresentando a maneira como Demétrio Poliorcetes é abordado na literatura, seja entre os escritores clássicos, como Plutarco e Diodoro da Sicília, ou entre os historiadores contemporâneos. Para Wheatley e Dunn (2020), representações de Demétrio Poliorcetes são largamente moldadas pela obra de Plutarco, um autor que teve como principal intenção produzir literatura e filosofia, além de disseminar lições de moral por meio de suas biografias. Nesse sentido, para Plutarco, a biografia de Demétrio possuía o objetivo de exemplificar, para o seu público, como a ambição corrompe um indivíduo e, segundo o autor grego, as derrotas e o destino de Demétrio são o resultado da personalidade daquele diádoco. Portanto, a imagem que persiste de Demétrio é a de um indivíduo degenerado, imprudente, fracassado, ambicioso e que procurava a todo momento emular Alexandre Magno. Afirmando que estão repudiando a dominante e tradicional representação de Demétrio sustentada por Plutarco, mas também notando que não procuram celebrizá-lo, Wheatley e Dunn (2020) seguem com um estudo em profundidade das evidências numismáticas, epigráficas e bibliográficas, em uma tentativa de juntar os fragmentos da vida de Demétrio e estabelecer uma coesa história deste indivíduo.

Como resultado, ao mesmo tempo que a obra é uma biografia de Demétrio, ela também produz uma análise crítica dos textos de, sobretudo, Plutarco e Diodoro da Sicília, e a todo instante Wheatley e Dunn (2020) procuram, com uma impressionante cautela, 
investigar os vieses por trás das anedotas e contos da vida de Demétrio. Plutarco e Diodoro escreveram ambos séculos após a morte de Demétrio, mas uma de suas fontes participou de inúmeras batalhas das Guerras dos Diádocos e pessoalmente acompanhou, em certos períodos, Antígono Monoftalmo e seu filho. Este historiador, Jerônimo da Cárdia, era um amigo de Eumenes e, após à derrota deste diádoco nas mãos de Antígono Monoftalmo, em 316 a.C., ele se juntou aos antigônidas. Apesar de que poucos fragmentos de Jerômino tenham sobrevivido, ele serviu como fonte para diversos historiadores na Antiguidade. Por conseguinte, Wheatley e Dunn (2020) procuram identificar, por um lado, como Plutarco criou ficções para aprimorar a qualidade literária de sua obra, em detrimento da história, e, por outro, como o viés pró-antigônida de Jerônimo pode ter atrapalhado as avaliações dos cursos de ação de Demétrio Poliorcetes por outros historiadores clássicos.

Nos primeiros capítulos da obra, o contexto histórico no qual Demétrio teve sua infância e juventude é apresentado, mas são poucos os detalhes disponíveis a respeito de sua família e de sua vida neste período. Posto que a atenção dos historiadores clássicos estava centrada em Alexandre Magno e suas campanhas militares, Wheatley e Dunn (2020) estabelecem o papel das conquistas e da reputação deste rei macedônio para a consolidação das aspirações e da personalidade de Demétrio. Em adição, nestas seções os autores discutem a importância central da Frígia, uma região que estava situada entre a Macedônia e os novos territórios conquistados por Alexandre Magno. Após uma parcial ocupação da Frígia, Alexandre responsabilizou Antígono Monoftalmo pelo governo desta satrápia enquanto ele continuava marchando rumo ao interior do Império Aquemênida. Depois de certo tempo, a família de Antígono Monoftalmo juntou-se a ele na Anatólia e, chegando na capital da Frígia por volta de seis anos de idade, Demétrio teve a educação de um nobre macedônio, mas num cenário atípico e em uma região cosmopolita.

Para Wheatley e Dunn (2020), a Frígia era provavelmente uma das regiões mais movimentadas naquele período, e com as conquistas de Alexandre Magno, em adição às próprias vitórias de Antígono Monoftalmo contra os persas no interior e nos arredores de sua satrápia, Demétrio, seu irmão e seus primos cresceram em meio a uma excitada atmosfera militar e durante eventos que já eram vistos como transformadores da história. Tendo em vista este ambiente, Wheatley e Dunn (2020) sugerem que há a possibilidade de que uma rivalidade entre Demétrio e seus primos, quando crianças, influenciou suas relações quando eles começaram a ter comandos militares independentes. Eventualmente, dois destes primos, um pouco mais velhos do que Demétrio, rebelaram-se contra Antígono Monoftalmo, e uma possível explicação para este fato é o favorecimento que Demétrio recebia de seu pai. 
Com o protagonismo de Antígono Monoftalmo durante as Guerras dos Diádocos, Demétrio finalmente aparece nos registros históricos. Wheatley e Dunn (2020) estabelecem como ele foi cuidadosamente preparado, por seu pai, para iniciar sua participação na cena político-militar. Em uma das batalhas de Antígono contra Eumenes, Demétrio foi alocado numa posição prestigiosa na cavalaria de seu pai, mas com seus flancos protegidos e cavalgando ao lado de experientes oficiais de Antígono. Em seguida, Wheatley e Dunn (2020) detalham as diversas campanhas e batalhas de Demétrio, como a Batalha de Gaza, em 312 a.C., sua campanha na Babilônia e seus enfrentamentos contra os nabateus. As relações de Demétrio com suas esposas também são um importante tópico de discussão, ao passo que os autores buscam estabelecer uma cronologia coerente dos eventos político-militares, em meio a registros históricos conflitantes. Ainda, as ações dos diádocos para com seus prisioneiros políticos, em conjunto com suas relações com as cidades gregas, são contextualizadas como parte de uma estratégia em busca da supremacia. Nessa perspectiva, os diádocos proclamavam que defendiam a independência das cidades gregas para se sobreporem a seus rivais e aumentarem suas esferas de influência. Enquanto isso, a rivalidade de Ptolomeu e Demétrio criou uma competição até nos bons tratos dos prisioneiros da outra dinastia, e repetidamente estes dois diádocos devolveram para o outro os familiares que foram capturados em batalha, não como um ato altruísta, mas sim como uma forma de humilhar o seu rival e se apresentar como um comandante honrado. Este foi o caso na Batalha de Salamina, em 306 a.C., quando Demétrio, após uma brilhante vitória, devolveu os familiares de Ptolomeu ao Egito.

Com a ilha de Chipre estando nas mãos antigônidas e a vitoriosa campanha de Demétrio em Atenas no ano de 307 a.C., Rodes e sua frota tinham que ser neutralizadas para a conquista de uma completa supremacia naval no leste do Mediterrâneo. Começando o sítio em 305 a.C., o cerco de Rodes deu a Demétrio sua reputação como um ávido sitiador, apesar de ter abandonado seu ataque um ano depois, pois seu pai the ordenou que o auxiliasse em outras regiões do Império Antigônida. Posto que o cerco não foi encerrado com completo sucesso, há uma perspectiva de que o epíteto de Demétrio, Poliorcetes, o "Sitiador de Cidades", tinha um significado indesejável para um comandante militar: ele era o sitiador, mas não o saqueador. Contudo, Wheatley e Dunn (2020) demonstram como a reputação de Demétrio fora fortalecida pelo cerco de Rodes e, após este evento, nenhuma cidade resistiu a seus ataques, sua reputação o precedendo.

Em 304 a.C., Demétrio retornou a Atenas. Para Wheatley e Dunn (2020), a narrativa de Plutarco a respeito da estadia de Demétrio nesta cidade é o principal fundamento de sua imagem negativa. Considerado como o libertador da cidade e tendo recebido inúmeras honras cívicas e divinas, Demétrio teria começado a agir de forma arrogante, prepotente 
e polêmica. Entretanto, os autores contextualizam estes eventos com as campanhas militares de Demétrio nos meses anteriores e posteriores, como também com o papel político da deificação deste diádoco para os interesses atenienses. A título de exemplo, um hino ateniense composto em honra de Demétrio, o hino itifálico, o colocava em um patamar acima dos deuses, pois ele tinha a capacidade de fornecer uma assistência real e tangível a esta cidade. Contudo, havia uma ressalva: o objetivo de tal honra era encorajar e desafiar Demétrio à ação, neste caso, lidar com os etólios que atacavam os atenienses.

Após a decisiva Batalha de Ipso, em 301 a.C., entre os antigônidas e a coalizão dos outros diádocos, Demétrio escapou em direção ao Mar Egeu com uma pequena parcela de suas forças. Posto que Diodoro da Sicília narra apenas os eventos até 302 a.C., a biografia de Plutarco é a mais expressiva fonte contínua a respeito dos últimos vinte anos da vida de Demétrio, o que dificulta a análise deste período. Mesmo se a narrativa de Plutarco fosse aceita sem questionamento, há várias lacunas em sua biografia, existindo certa deturpação temporal, pois o autor não descreve em profundidade a extensão do domínio de Demétrio no início do século III a.C. Portanto, Wheatley e Dunn (2020) recorrem primariamente às evidências numismáticas para avaliarem a posição de Demétrio nestes anos, como também para identificarem os territórios que ele ainda dominava.

Por meio de uma profunda investigação das moedas produzidas nestes anos ao longo da Grécia, Anatólia e Síria, os autores detalham o que Demétrio conseguiu salvar do Império Antigônida, este que fora nominalmente dividido entre Ptolomeu, Cassandro, Lisímaco e Seleuco após 301 a.C. A título de exemplo, a cidade de Tiro continuou produzindo moedas no estilo de Demétrio até 294 a.C., quando finalmente começou a produzir moedas ptolomaicas, o que sugere que Demétrio, provavelmente em razão de sua superioridade naval, conseguira manter o controle desta cidade até então. Inúmeras outras cidades costeiras na Anatólia também continuaram produzindo moedas de Demétrio, e neste período seu retrato aparece pela primeira vez nas evidências numismáticas, usando o diadema, o símbolo helenístico da realeza, e possuindo um chifre em sua têmpora, um símbolo ligado a Poseidon. Nesta Era dos Diádocos, associarse aos deuses tinha importantes implicações políticas e, para Wheatley e Dunn (2020), tais pretensões eram provavelmente úteis politicamente para tais indivíduos, como também para as cidades que devotavam tais honras a diádocos específicos. Ainda, como Demétrio dependia primariamente de suas forças navais para manter o controle de suas regiões de 300 a.C. em diante, o uso de símbolos do deus do mar provavelmente tinha a intenção de realçar a conexão entre eles e prestigiar sua frota. Enquanto isso, a presença do diadema pode ser atribuída, segundo os autores, à insegurança de Demétrio após 
Ipso, sendo uma maneira de demonstrar uma continuidade no reino antigônida e o status de Demétrio como rei.

Para os autores, Demétrio começou a recuperar seu papel no cenário político já em 300 a.C., posto que várias regiões críticas para o Império Antigônida, como a ilha de Chipre e as cidades de Corinto e Éfeso, permaneceram sob o controle de Demétrio. Sua primeira campanha significativa após Ipso foi uma incursão aos territórios de Lisímaco com o objetivo de criar o caos no reino deste diádoco, reconstruir sua reputação e conseguir recursos para pagar seus soldados e sua frota. Os cursos de ação de Demétrio após Ipso não apenas refletem suas elevadas ambições, mas também demonstram que ele conseguiu minimizar os efeitos desta catastrófica batalha por meio de uma estratégia eficaz que fazia o melhor uso de seu principal trunfo, a frota antigônida. Por sua estratégia e a reorganização da cunhagem de suas moedas, a caracterização de Demétrio é a de um comandante que avaliou corretamente o cenário entre os outros diádocos e, também, seus próprios constrangimentos econômicos e políticos após 301 a.C. Suas ações certamente produziram frutos e já em 299 a.C. o cenário político começou a se alterar, com uma nova leva de alianças, por meio de casamentos entre membros das dinastias, sendo realizada.

Seleuco se casou com Estratonice, filha de Demétrio, e esta aliança era exatamente o que ele precisava para continuar o seu retorno ao protagonismo. Sem a ameaça de interferência de Seleuco, Demétrio conseguiu ocupar mais regiões de Lisímaco e Ptolomeu, como a Cilícia. Todavia, sua aliança com Seleuco eventualmente enfraqueceu, e Lisímaco, Ptolomeu e Seleuco se juntaram novamente para erradicarem Demétrio por completo. Por volta de 294 a.C., quando Demétrio estava na Grécia, a ilha de Chipre, como também as regiões antigônidas na Anatólia e Síria, foram ocupadas pelos outros diádocos.

Demétrio havia viajado em direção a Atenas ao observar uma oportunidade de retomar sua influência na Grécia e, possivelmente, interferir no reino da Macedônia após a morte de Cassandro. Demétrio sitiou Atenas e, após sua vitória, iniciou uma campanha no Peloponeso, ganhando o controle de uma parte expressiva da Grécia enquanto os outros diádocos atacavam suas cidades na Anatólia. Ele não possuía o poder militar para responder ao ataque combinado de três diádocos em suas regiões costeiras no leste do Mediterrâneo e, em vez disso, ele se moveu a Norte, na direção da Macedônia. Segundo Wheatley e Dunn (2020), as diversas operações de Demétrio neste período, em Atenas, no Peloponeso e, posteriormente, na Macedônia, podem compor entre si uma estratégia mais ampla e coesa. Nessa perspectiva, Demétrio escapou preventivamente de um inevitável combate na Ásia, contra os três mais poderosos diádocos, para operar na Grécia. O resultado de seu curso de ação foi a ocupação de uma grande parte desta região e, ainda, a conquista do reino da Macedônia. 
Com esta nova base de poder, Demétrio começou os preparativos para a invasão da Ásia, focando seus esforços na reunião de recursos, navios e soldados. Nestes anos a produção de moedas nas regiões sob seu domínio cresceu de forma significativa, isto compondo apenas uma parte das intensivas preparações de Demétrio. Entretanto, os outros diádocos avançaram primeiro, e Lisímaco atacou a Macedônia pelo Leste, Pirro de Épiro avançou pelo Oeste, e Ptolomeu navegou com sua frota ao sul da Grécia. Deixando seu filho, Antígono Gônatas, em controle da Grécia, Demétrio marchou para enfrentar Lisímaco e Pirro, mas seu exército se rebelou e ele perdeu o controle da Macedônia. Eventualmente, ele iria iniciar sua invasão da Ásia, mas com um exército enxuto e, após uma conturbada expedição, foi capturado por Seleuco. Na conclusão da obra, Wheatley e Dunn (2020) oferecem um balanço da vida de Demétrio. Para os autores, é comum deixar o destino ditar o tom da jornada. De fato, Demétrio terminou sua vida como um prisioneiro após sofrer diversos fracassos. Contudo, para Wheatley e Dunn (2020) tal resultado foi uma consequência do contexto político e não de sua personalidade. Mesmo assim, os autores notam que Demétrio teve um impacto profundo nos impérios que emergiram durante sua vida, e seu legado seria perpetuado por Antígono Gônatas, este que conseguiu no fim retomar o controle do reino da Macedônia.

Certamente, esta obra é tão impactante, aos estudos dos diádocos e de seus conflitos, quanto a pesquisa de Richard Billows (1990) a respeito de Antígono Monoftalmo. A aproximação holística entre as evidências numismáticas, epigráficas e bibliográficas feita pelos autores não só resulta numa biografia compreensiva de Demétrio Poliorcetes, mas também inevitavelmente auxiliará nos estudos de Plutarco e das Guerras dos Diádocos como um todo. Em suma, a lacuna na historiografia dos diádocos foi habilmente preenchida pela obra Demetrius the Besieger, e a contribuição de Wheatley e Dunn para os estudos helenísticos e, sobretudo, dos antigônidas, é colossal. A sombra de Plutarco sob a imagem de Demétrio Poliorcetes está, sem dúvida alguma, enfraquecida após este extenso volume.

\section{Referências}

ANDRÉ, A. A fabricação da 'basileia' helenística: um estudo sobre o governo de Antígono Monoftalmo e Demétrio Poliorcetes (321-301 a.C.). 2018. Tese (Doutorado em História) - Universidade Federal do Espírito Santo, Vitória, 2018.

BERNARDINO, D. O diadema e Alexandre: a gênese da representação real helenística. Figura: Studies on the Classical Tradition, v. 8, n. 2, p. 36-70, 2020. 
BILLOWS, R. Antigonos the One-Eyed and the creation of the Hellenistic State. Berkeley: University of California Press, 1990.

CHAMPION, J. Antigonus the One-Eyed: greatest of the successors. Barnsley: Pen \& Sword Military, 2014.

SANT'ANNA, H. Antígono versus Eumenes ou a luta pela supremacia política nos primórdios da história helenística, 323-301 a.C. Opsis, v. 12, n. 2, p. 232-246, 2012. WHEATLEY, P.; DUNN, C. Demetrius the Besieger. Oxford: Oxford University Press, 2020. 